\title{
EKSPERIMENTASI MODEL PEMBELAJARAN KOOPERATIF TIPE JIGSAW DAN NUMBERED HEADS TOGETHER PADA POKOK BAHASAN BANGUN RUANG SISI DATAR DITINJAU DARI KECERDASAN INTERPERSONAL SISWA KELAS VIII SMP NEGERI DI KOTA MADIUN
}

\author{
Kiki Riska Ayu Kurniawati ${ }^{1}$, Budiyono ${ }^{2}$, dan Dewi Retno Sari Saputro ${ }^{3}$ \\ ${ }^{1,2,3}$ Program Magister Pendidikan Matematika, FKIP UNS Surakarta
}

\begin{abstract}
The aims of this research were to find out the different effect of each categories of learning model, students interpersonal intelligence and their interaction towards students mathematics learning achievement on the subject of plane geometry. The research was quasi experimental with $3 \times 3$ factorial design. The population was all students of grade VIII State Junior High School in Madiun City on the second semester of 2013/2014 academic years. Sampling was done by stratified cluster random sampling technique. The sample of this research consisted of the students of SMP N 3 Madiun, SMPN 7 Madiun, and SMPN 10 Madiun. The sample consisted of 260 students. The hypothesis test used unbalanced two ways analysis of variance at the significance level of 0,05 . Based on hypothesis test, it can be concluded that: (1) the cooperative learning model of Jigsaw type gives a better mathematics achievement than cooperative learning model of NHT type and direct learning model, and the cooperative learning model of NHT type gives a better mathematics achievement than direct learning model; (2) students with the high interpersonal intelligence had the same achievement as students with the medium interpersonal intelligence, students with the high interpersonal intelligence had better achievement than students with the low interpersonal intelligence and the students with the medium interpersonal intelligence had the same achievement as students with the low interpersonal intelligence; (3) on the cooperative learning model of Jigsaw type, NHT type and direct learning model, students with the high interpersonal intelligence had the same achievement as students with the medium interpersonal intelligence, students with the high interpersonal intelligence had better achievement than students with the low interpersonal intelligence and the students with the medium interpersonal intelligence had the same achievement as students with the low interpersonal intelligence; and (4) on students interpersonal intelligence high, medium and low, the cooperative learning model of Jigsaw type gives a better mathematics achievement than cooperative learning model of NHT type and direct learning model, and the cooperative learning model of NHT type gives a better mathematics achievement than direct learning model.
\end{abstract}

Keywords: Jigsaw, NHT, interpersonal intelligence

\section{PENDAHULUAN}

Kemajuan suatu bangsa sangat ditentukan oleh kualitas sumber daya manusia, sedangkan kualitas sumber daya manusia tergantung pada kualitas pendidikannya. Oleh karena itu, pembaharuan pendidikan harus selalu dilakukan untuk meningkatkan kualitas pendidikan suatu bangsa. Upaya peningkatan kualitas pembelajaran khususnya mata pelajaran matematika harus terus diupayakan, baik oleh guru maupun semua pihak yang terkait langsung dalam penyelenggaraan pendidikan di Indonesia. Menurut Naomi dan 
Githua (2013: 177), bahwa pengetahuan matematika sebagai alat untuk digunakan dalam kehidupan sehari-hari adalah penting bagi keberadaan setiap individu dan masyarakat.

Prestasi belajar siswa dalam matematika dipengaruhi beberapa faktor eksternal maupun internal. Faktor eksternal dalam permasalahan ini adalah model mengajar guru. Menurut Ewing (2011:68), pembelajaran langsung merupakan pembelajaran yang berpusat pada guru dan fokus pada cara mengajar guru dengan komunikasi yang jelas, sedangkan guru dituntut untuk mendorong siswa belajar secara aktif dan dapat meningkatkan kemampuan dalam memahami suatu konsep dalam matematika. Banyak usaha yang dilakukan guru untuk mempermudah pembelajaran matematika, salah satunya adalah dengan menggunakan model pembelajaran yang sesuai dengan bahan pelajaran dan berupaya melibatkan keaktifan siswa dalam pembelajaran agar lebih bermakna dalam belajar, tetapi pada kenyataan secara visual, pelaksanaan proses pembelajaran siswa hanya duduk diam mendengarkan ceramah dari guru, kemudian guru cenderung mengajar dengan tujuan menyelesaikan materi pelajaran sesuai dengan kurikulum, sehingga hasil yang diperoleh siswa hanya bersifat sementara. Dalam proses ini, siswa sering mengalami kesulitan dalam menyelesaikan soal matematika. Kesulitan ini tidak hanya karena materi yang sulit tetapi juga karena model pembelajaran yang digunakan guru kurang tepat, tidak menarik bahkan tidak relevan dengan kurikulum yang berlaku, sehingga siswa kurang termotivasi dalam belajar matematika. Menurut Goos (2004: 259), proses belajar tradisional adalah proses belajar mengandalkan buku, siswa hanya melihat dan mendengar guru mengajar prosedur matematika dan akhirnya siswa mengerjakan latihan.

Sehubungan dengan hal tersebut, untuk mengatasi permasalahan yang dihadapi siswa dalam mempermudah pembelajaran matematika, salah satunya dengan menerapkan model pembelajaran yang sesuai dengan karakteristik siswa, yaitu model pembelajaran kooperatif, dimana menurut Damon dan Phelps (dalam Cheong, 2010: 75), pembelajaran kooperatif adalah kegiatan berbasis kelompok yang biasanya terdiri dari 5-6 individu dan disajikan dengan tugas untuk dipecahkan. Individu-individu dalam kelompok dikelompokkan heterogen dan masing-masing diberikan peran yang nantinya dapat saling tukar informasi antar individu. Tidak semua kerja kelompok bisa dianggap cooperative learning. Untuk mencapai hasil yang maksimal, Johnson dan Holubec (dalam Zakaria dan Iksan, 2006: 36) mengusulkan lima unsur penting dari pembelajaran kooperatif, diantaranya yaitu: (1) saling ketergantungan positif antar siswa; (2) interaksi promotif dengan saling membantu dan memberikan umpan balik; (3) tanggung jawab individu; (4) interpersonal dan keterampilan kelompok kecil; serta (5) proses berkelompok yang 
memusatkan hubungan kerjasama yang baik, memudahkan keterampilan kooperatif dan memastikan anggota kelompok menerima umpan balik.

Dua diantara model pembelajaran kooperatif tersebut yaitu pembelajaran kooperatif tipe Jigsaw dan Numbered Heads Together (NHT). Menurut Sengul dan Katranci (2012: 3), dalam model pembelajaran Jigsaw semua siswa dalam kelompok Jigsaw mempelajari subjek tertentu bersama-sama dan setelah itu, siswa kembali ke kelompok asal dan membagi pengetahuannya, sedangkan menurut Baker (2013: 6), NHT menciptakan saling ketergantungan positif dan akuntabilitas atau pertanggungjawaban individu dalam kelompok yang terdiri dari empat siswa, karena masing-masing individu mempunyai potensi untuk bertanggungjawab atas keberhasilan kelompoknya apabila nomornya dipanggil.

Alasan membandingkan dua model pembelajaran tersebut sejalan dengan beberapa penelitian yg dilakukan oleh Maheady et al. (2006) yang menyatakan bahwa NHT merupakan pembelajaran yang efisien dan efektif meningkatkan keaktifan dan memperbaiki prestasi. Selanjutnya, penelitian oleh Ahmad dan Jazuli (2009) yang menyatakan bahwa kemampuan komunikasi matematika siswa yang belajar menggunakan pembelajaran kooperatif tipe Jigsaw lebih baik daripada menggunakan model pembelajaran konvensional, serta penelitian oleh Tran dan Lewis (2012) yang menyatakan bahwa penelitiannya memperkaya pemahaman tentang bagaimana dan mengapa pembelajaran Jigsaw memberikan kontribusi terhadap prestasi akademik tinggi mahasiswa Vietnam dan retensi pengetahuan.

Selain model pembelajaran yang digunakan oleh guru, faktor internal dalam diri siswa juga perlu diperhatikan dalam proses pembelajaran. Salah satu faktor internal dalam diri siswa, yakni kecerdasan. Menurut Zarei dan Mohseni (2012: 1307), Gardner percaya bahwa kecerdasan lebih dari satu di dalam pikiran manusia, semua siswa tidak hanya cerdas secara verbal atau secara matematis, mereka mungkin mempunyai keahlian di bidang lain. Kecerdasan yang dimiliki siswa-siswa pastinya sangat beragam (Multiple Intellegence). "The multiple intelligences theory was originally proposed by psychologist Howard Gardner at Harvard University in 1983. He defined eight measures of multiple intelligence: linguistics, logical-mathematics, visual-spatial, interpersonal, intrapersonal, musical, bodily-kinesthetic and naturalist" (Amstrong dalam Xie dan Lin, 2009: 106). Adapun dari kedelapan kecerdasan tersebut, gambaran umum tentang permasalahan kurangnya komunikasi antar siswa mengenai materi pelajaran yang diterima selama proses pembelajaran, karena jarang diterapkannya pembelajaran yang mengkondisikan 
siswa untuk belajar secara berkelompok di kelas, sehingga yang terjadi adalah pembelajaran selama ini hanya berjalan komunikasi satu arah, yaitu komunikasi dari guru ke siswa dan tidak ada feedback dari siswa. Hal ini adalah salah satu alasan mengapa peneliti ingin melakukan penelitian dengan tinjauan kecerdasan interpersonal siswa. Chan (2005: 188) berpendapat bahwa kecerdasan interpersonal adalah kemampuan untuk memahami dan berinteraksi secara efektif dengan orang lain. Dalam konteks belajar, ia lebih suka belajar bersama orang lain, lebih suka mengadakan studi kelompok (Paul Suparno, 2013: 39-40).

Adapun tujuan penelitian ini adalah untuk mengetahui: 1) manakah yang memberikan prestasi belajar matematika siswa yang lebih baik, model pembelajaran kooperatif tipe Jigsaw, NHT atau langsung; 2) manakah yang mempunyai prestasi belajar matematika yang lebih baik, siswa dengan kecerdasan interpersonal tinggi, sedang atau rendah; 3) pada masing-masing model pembelajaran, manakah yang memberikan prestasi belajar matematika yang lebih baik, siswa dengan kecerdasan interpersonal tinggi, sedang atau rendah; dan 4) pada masing-masing tingkatan kecerdasan interpersonal siswa, manakah yang memberikan prestasi belajar matematika yang lebih baik, model pembelajaran kooperatif tipe Jigsaw, NHT atau langsung.

\section{METODE PENELITIAN}

Penelitian ini dilaksanakan pada seluruh siswa SMP Negeri di Kota Madiun, dan subjek penelitiannya adalah siswa kelas VIII semester genap tahun ajaran 2013/2014. Dalam penelitian ini, jenis penelitian yang digunakan adalah penelitian eksperimental semu, dimana responden dikelompokkan menjadi tiga kelompok, yaitu kelompok Jigsaw sebagai eksperimen satu, kelompok NHT sebagai eksperimen dua, dan kelompok pembelajaran langsung sebagai kontrol. Desain faktorial yang digunakan dalam penelitian ini adalah $3 \times 3$. Teknik pengambilan sampel dilakukan dengan cara stratified cluster random sampling, yaitu dengan cara pengelompokkan sekolah berdasarkan peringkat nilai ujian nasional matematika tingkat Kota Madiun menjadi kelompok tinggi, sedang dan rendah. Masing- masing kategori dipilih satu sekolah dan dari masing-masing sekolah yang terpilih diambil 3 kelas secara acak. Dari pengambilan sampel, diperoleh sampel yaitu SMPN 3 Madiun dari kategori tinggi, SMPN 7 Madiun dari kategori sedang, dan SMPN 10 Madiun dari kategori rendah. Variabel bebas dalam penelitian ini adalah model pembelajaran dan kecerdasan interpersonal, dan variabel terikatnya adalah prestasi belajar matematika. 
Metode pengumpulan data penelitian meliputi metode dokumentasi yang berupa hasil nilai UAS semester ganjil tahun ajaran 2013/2014, metode tes yang berupa 25 butir soal pilihan ganda pada pokok bahasan bangun ruang sisi datar, dan metode angket yang berupa 40 butir angket untuk mengetahui tingkatan kecerdasan interpersonal siswa. Setelah data diperoleh dari pelaksanaan penelitian, yang dilaksanakan selanjutnya adalah pengujian terhadap data tersebut. Adapun pengujian data meliputi uji keseimbangan yang digunakan untuk menguji dua rataan kelas eksperimen dan kelas kontrol. Uji keseimbangan pada penelitian ini menggunakan anava satu jalan sel tak sama dengan uji prasyarat uji normalitas menggunakan metode Lilliefors dan uji homogenitas dengan Bartlett. Selanjutnya, uji hipotesis data dalam penelitian ini menggunakan analisis variansi dua jalan sel tak sama. Tujuan dari analisis variansi dua jalan ini adalah untuk menguji signifikansi faktor baris, faktor kolom dan kombinasi faktor baris dan kolom terhadap prestasi belajar, serta uji komparasi ganda. Jika hasil dari analisis variansi dua jalan sel tidak sama tersebut menunjukkan $H_{0}$ nya ditolak, maka dilakukan uji komparasi ganda pasca anava dengan menggunakan metode Scheffe'.

\section{HASIL PENELITIAN DAN PEMBAHASAN}

Sebelum penelitian ini dilakukan, terlebih dahulu harus dilakukan uji keseimbangan rata-rata antar ketiga populasi. Hal ini dilakukan untuk mengetahui keadaan kemampuan awal antara ketiga populasi, yaitu kelas eksperimen satu, kelas eksperimen dua dan kelas kontrol dalam kedudukan yang seimbang atau tidak. Adapun data yang digunakan sebagai kemampuan awal ketiga populasi ini adalah prestasi belajar matematika dari nilai matematika siswa pada UAS semester ganjil ketiga SMP Negeri di Madiun, yaitu SMPN 3 Madiun, SMPN 7 Madiun dan SMPN 10 Madiun.

Berdasarkan hasil uji keseimbangan yang telah dilakukan, diperoleh nilai $F_{\mathrm{obs}}=$ $1,98<3=F_{\alpha}$, maka $H_{0}$ diterima, sehingga dapat disimpulkan bahwa ketiga populasi mempunyai kemampuan awal yang sama atau seimbang. Selanjutnya, data yang digunakan dalam pengujian hipotesis adalah data prestasi belajar matematika siswa pada pokok bahasan bangun ruang sisi datar. Berikut disajikan rerata tes prestasi belajar matematika siswa dalam model pembelajaran dan kategori kecerdasan interpersonal siswa pada Tabel 1. 
Tabel 1 Rerata Tes Prestasi Belajar Matematika Siswa dalam Model Pembelajaran dan Kategori Kecerdasan Interpersonal Siswa

\begin{tabular}{lcccc}
\hline \multirow{2}{*}{$\begin{array}{c}\text { Model } \\
\text { Pembelajaran }\end{array}$} & \multicolumn{3}{c}{$\begin{array}{c}\text { Rata-rata Tes Prestasi Belajar } \\
\text { Matematika berdasarkan Kecerdasan }\end{array}$} & \multirow{2}{*}{$\begin{array}{c}\text { Rerata } \\
\text { Marginal }\end{array}$} \\
\cline { 2 - 4 } & \multicolumn{3}{c}{ Interpersonal Siswa } & \\
\hline Jigsaw & 73,6923 & 65,7500 & 66,8000 & 68,4545 \\
NHT & 66,7200 & 60,0000 & 57,7143 & 61,1954 \\
Langsung & 59,2632 & 58,0000 & 46,2400 & 55,1059 \\
\hline \hline Rerata Marginal & 65,5730 & 61,5909 & 57,5422 & \\
\hline
\end{tabular}

Sebelum melanjutkan dalam uji hipotesis, salah satu syarat untuk analisis variansi adalah dilakukan uji normalitas dan uji homogenitas. Berikut perhitungan uji normalitas dan uji homogenitas disajikan secara berturut pada Tabel 2 dan Tabel 3.

Tabel 2 Rangkuman Hasil Uji Normalitas

\begin{tabular}{lcccc}
\hline \multicolumn{1}{c}{ Sampel } & $L_{\mathrm{obs}}$ & $L_{\alpha}$ & $\begin{array}{c}\text { Keputusan } \\
\text { Uji }\end{array}$ & Kesimpulan \\
\hline Jigsaw & 0,0811 & 0,0944 & $H_{0}$ diterima & Normal \\
NHT & 0,0892 & 0,0950 & $H_{0}$ diterima & Normal \\
Langsung & 0,0786 & 0,0961 & $H_{0}$ diterima & Normal \\
$\begin{array}{l}\text { Kecerdasan interpersonal } \\
\text { siswa tinggi }\end{array}$ & 0,0632 & 0,0939 & $H_{0}$ diterima & Normal \\
$\begin{array}{l}\text { Kecerdasan interpersonal } \\
\text { siswa sedang }\end{array}$ & 0,0880 & 0,0944 & $H_{0}$ diterima & Normal \\
$\begin{array}{l}\text { Kecerdasan interpersonal } \\
\text { siswa rendah }\end{array}$ & 0,0954 & 0,0973 & $H_{0}$ diterima & Normal \\
\hline
\end{tabular}

Tabel 3 Rangkuman Hasil Uji Homogenitas Variansi

\begin{tabular}{|c|c|c|c|c|}
\hline $\begin{array}{l}\text { Populasi Siswa } \\
\text { Antar }\end{array}$ & $\chi_{\text {obs }}^{2}$ & $\chi_{\alpha}^{2}$ & Keputusan uji & Kesimpulan \\
\hline Model Pembelajaran & 0,6614 & 5,991 & $H_{0}$ diterima & $\begin{array}{c}\text { Variansi ketiga } \\
\text { populasi homogen }\end{array}$ \\
\hline $\begin{array}{l}\text { Kecerdasan Interpersonal } \\
\text { Siswa }\end{array}$ & 0,0201 & 5,991 & $H_{0}$ diterima & $\begin{array}{c}\text { Variansi ketiga } \\
\text { populasi homogen }\end{array}$ \\
\hline
\end{tabular}

Hasil uji prasyarat pada tabel tersebut diperoleh kesimpulan bahwa sampel berasal dari populasi yang berdistribusi normal dan mempunyai variansi yang homogen. Setelah prasyarat analisis variansi terpenuhi, dilakukan uji hipotesis analisis variansi dua jalan sel tak sama yang hasilnya seperti pada Tabel 4. 
Tabel 4 Rangkuman Analisis Variansi Dua Jalan Sel Tak Sama

\begin{tabular}{|c|c|c|c|c|c|c|}
\hline Sumber & JK & $\mathrm{dk}$ & RK & $F_{\text {obs }}$ & $F_{\alpha}$ & Keputusan \\
\hline Pembelajaran $(A)$ & 8565,1250 & 2 & 4282,5625 & 16,4817 & 3,00 & $H_{0 \mathrm{~A}}$ ditolak \\
\hline $\begin{array}{l}\text { Kecerdasan } \\
\text { interpersonal }(B)\end{array}$ & 3934,9214 & 2 & 1967,4607 & 7,5719 & 3,00 & $H_{0 \mathrm{~B}}$ ditolak \\
\hline Interaksi $(A B)$ & 1247,2947 & 4 & 311,8237 & 1,2001 & 2,37 & $H_{0 \mathrm{AB}}$ diterima \\
\hline Galat $(G)$ & 65219,0212 & 251 & 259,8367 & - & - & \\
\hline Total $(T)$ & 78966,3623 & 259 & - & - & - & \\
\hline
\end{tabular}

Kesimpulan analisis variansi dua jalan sel tak sama berdasarkan Tabel 4 adalah: 1) pada efek utama $(A)$, siswa dengan model pembelajaran Jigsaw, siswa dengan model pembelajaran NHT dan siswa dengan model pembelajaran langsung menghasilkan prestasi belajar matematika yang berbeda, 2) pada efek utama (B), ketiga kategori kecerdasan interpersonal memberikan efek yang berbeda terhadap prestasi belajar matematika, dan 3) pada efek interaksi $(A B)$, tidak ada interaksi antara model pembelajaran yang digunakan dan kecerdasan interpersonal siswa terhadap prestasi belajar matematika.

Dari kesimpulan tersebut, diketahui bahwa $H_{0 \mathrm{~A}}$ dan $H_{0 \mathrm{~B}}$ ditolak, sehingga perlu dilakukan uji komparasi rerata antar baris dan kolom. Adapun hasil uji komparasi rerata antar baris dan kolom disajikan pada Tabel 5 dan Tabel 6 .

Tabel 5 Komparasi Rerata Prestasi Belajar Matematika Antar Model Pembelajaran

\begin{tabular}{crrc}
\hline$H_{0}$ & \multicolumn{1}{c}{$F_{\text {obs }}$} & $2 . F_{\alpha}$ & Keputusan Uji \\
\hline$\mu_{1 .}=\mu_{2 .}$ & 8,8723 & 6,00 & $H_{0}$ ditolak \\
$\mu_{1 .}=\mu_{3 .}$ & 29,6504 & 6,00 & $H_{0}$ ditolak \\
$\mu_{2 .}=\mu_{3 .}$ & 6,1359 & 6,00 & $H_{0}$ ditolak \\
\hline
\end{tabular}

Berdasarkan Tabel 5, diperoleh kesimpulan komparasi rerata antar baris sebagai berikut. 1) Pada $F_{1-2}\left(\mu_{1 .}=\mu_{2}\right)$ diketahui bahwa nilai $H_{0}$ ditolak, artinya terdapat perbedaan signifikan antara prestasi belajar matematika siswa yang diberi model pembelajaran Jigsaw maupun prestasi belajar matematika siswa yang diberi model pembelajaran NHT. Ini berarti jika dilihat dari rerata marginalnya, siswa yang diberikan model pembelajaran kooperatif tipe Jigsaw $(68,4545)$ menghasilkan prestasi belajar matematika yang lebih baik dibandingkan siswa yang diberikan model pembelajaran kooperatif tipe NHT $(61,1954)$. 2) Pada $F_{1-3}\left(\mu_{1}=\mu_{3}\right.$. ) diketahui bahwa nilai $H_{0}$ ditolak, artinya terdapat perbedaan signifikan antara prestasi belajar matematika siswa yang diberi model pembelajaran Jigsaw dengan prestasi belajar matematika siswa yang diberi model 
pembelajaran langsung. Ini berarti jika dilihat dari rerata marginalnya, siswa yang diberikan model pembelajaran kooperatif tipe Jigsaw $(68,4545)$ menghasilkan prestasi belajar matematika yang lebih baik dibandingkan siswa yang diberikan model pembelajaran langsung $(55,1059)$. 3) Pada $F_{2-3}\left(\mu_{2 .}=\mu_{3}\right.$.) diketahui bahwa nilai $H_{0}$ ditolak, artinya terdapat perbedaan signifikan antara prestasi belajar matematika siswa yang diberi model pembelajaran NHT dengan prestasi belajar matematika siswa yang diberi model pembelajaran langsung. Ini berarti jika dilihat dari rerata marginalnya, siswa yang diberikan model pembelajaran kooperatif tipe NHT $(61,1954)$ menghasilkan prestasi belajar matematika yang lebih baik dibandingkan siswa yang diberikan model pembelajaran langsung $(55,1059)$.

Hasil ini sesuai dengan beberapa penelitian yang dilakukan oleh Ahmad dan Jazuli (2009) yang menyatakan bahwa kemampuan komunikasi matematika siswa yang belajar menggunakan pembelajaran kooperatif tipe Jigsaw lebih baik daripada menggunakan model pembelajaran konvensional. Penelitian Sulani (2010) yang menyatakan bahwa prestasi belajar matematika pada materi pokok sistem persamaan linear yang mendapat pembelajaran dengan model kooperatif tipe Jigsaw lebih baik daripada yang mendapat pembelajaran langsung. Selanjutnya, penelitian Tran dan Lewis (2012) yang menyatakan pemahaman tentang bagaimana dan mengapa pembelajaran Jigsaw memberikan kontribusi terhadap prestasi akademik tinggi mahasiswa Vietnam dan retensi pengetahuan. Lebih lanjut, penelitian Naomi (2013) yang menunjukkan bahwa siswa yang diajarkan menggunakan pembelajaran kooperatif Jigsaw menghasilkan prestasi belajar yang lebih baik daripada yang diajarkan menggunakan pembelajaran konvensional, dan penelitian Katherine Her Pratiwi (2013) menyimpulkan bahwa model pembelajaran Jigsaw memberikan prestasi belajar matematika yang lebih baik daripada model pembelajaran NHT dan pembelajaran langsung, dan model pembelajaran NHT memberikan prestasi belajar matematika yang lebih baik daripada model pembelajaran langsung, serta penelitian Maheady et al. (2006) yang menyatakan bahwa NHT merupakan pembelajaran yang efisien dan efektif dalam meningkatkan keaktifan dan memperbaiki prestasi. 
Tabel 6 Komparasi Rerata Prestasi Belajar Matematika Antar Kecerdasan Interpersonal Siswa

\begin{tabular}{crrc}
\hline$H_{0}$ & \multicolumn{1}{c}{$F_{\text {obs }}$} & $2 . F_{\alpha}$ & Keputusan Uji \\
\hline$\mu_{.1}=\mu_{.2}$ & 2,7004 & 6,00 & $H_{0}$ diterima \\
$\mu_{.1}=\mu_{.3}$ & 10,6602 & 6,00 & $H_{0}$ ditolak \\
$\mu_{.2}=\mu_{.3}$ & 2,6947 & 6,00 & $H_{0}$ diterima \\
\hline
\end{tabular}

Selanjutnya, berdasarkan Tabel 6, diperoleh kesimpulan komparasi rerata antar kolom sebagai berikut. 1) Pada $F_{1-2}\left(\mu_{.1}=\mu_{2 .}\right)$ diketahui bahwa nilai $H_{0}$ diterima, artinya tidak terdapat perbedaan signifikan antara prestasi belajar matematika siswa yang mempunyai kecerdasan interpersonal tinggi maupun prestasi belajar matematika siswa yang mempunyai kecerdasan interpersonal sedang. Ini berarti siswa dengan kecerdasan interpersonal tinggi mempunyai prestasi belajar matematika yang sama baiknya dengan siswa yang mempunyai kecerdasan interpersonal sedang. 2) Pada $F_{1-3}\left(\mu_{.1}=\mu_{3.3}\right)$ diketahui bahwa nilai $H_{0}$ ditolak, artinya terdapat perbedaan signifikan antara prestasi belajar matematika siswa yang mempunyai kecerdasan interpersonal tinggi dengan prestasi belajar matematika siswa yang mempunyai kecerdasan interpersonal rendah. Ini berarti jika dilihat dari rerata marginalnya, siswa dengan kecerdasan interpersonal tinggi $(65,5730)$ mempunyai prestasi belajar matematika yang lebih baik dibandingkan dengan siswa yang mempunyai kecerdasan interpersonal rendah (57,5422). 3) Pada $F_{2-3}\left(\mu_{.2}=\mu_{.3}\right)$ diketahui bahwa nilai $H_{0}$ diterima, artinya tidak terdapat perbedaan signifikan antara prestasi belajar matematika siswa yang mempunyai kecerdasan interpersonal sedang dengan prestasi belajar matematika siswa yang mempunyai kecerdasan interpersonal rendah. Ini berarti siswa dengan kecerdasan interpersonal sedang mempunyai prestasi belajar matematika yang sama dengan siswa yang mempunyai kecerdasan interpersonal rendah.

Hasil penelitian ini sesuai dengan beberapa penelitian yang dilakukan oleh Erlyn Yustantina (2012) dalam penelitiannya yang menunjukkan bahwa penggunaan model pembelajaran tipe Student Team Achievement Divisions (STAD) pada siswa yang mempunyai kecerdasan interpersonal tinggi, memperoleh skor prestasi hasil belajar ratarata lebih baik dibandingkan dengan siswa yang mempunyai kecerdasan interpersonal rendah. Selanjutnya, penelitian oleh Sulistyana (2013), yang menyimpulkan bahwa siswa yang mempunyai kecerdasan interpersonal tinggi, menghasilkan prestasi belajar lebih baik dibandingkan dengan siswa yang mempunyai kecerdasan interpersonal rendah, dan 
penelitian Arianti Puspita Dewi (2014) yang menunjukkan bahwa siswa dengan kecerdasan interpersonal tinggi mempunyai prestasi belajar matematika lebih baik daripada siswa dengan kecerdasan interpersonal rendah.

Dari analisis variansi dua jalan, diketahui bahwa $H_{0 \mathrm{AB}}$ diterima, sehingga tidak perlu dilakukan uji lanjut pasca analisis variansi dengan metode Scheffe' untuk uji komparasi rerata antar sel pada kolom yang sama dan uji komparasi rerata antar sel pada baris yang sama. Berdasarkan kesimpulan pada hipotesis antar baris dan antar kolom, maka dapat disimpulkan sebagai berikut. 1) Pada masing-masing model pembelajaran, bahwa antara siswa yang mempunyai kecerdasan interpersonal tinggi menghasilkan prestasi belajar yang sama baiknya dibandingkan dengan siswa yang mempunyai kecerdasan interpersonal sedang, siswa yang mempunyai kecerdasan interpersonal tinggi mempunyai prestasi belajar yang lebih baik dibandingkan dengan siswa yang mempunyai kecerdasan interpersonal rendah, dan siswa yang mempunyai kecerdasan interpersonal sedang menghasilkan prestasi belajar yang sama baiknya dibandingkan dengan siswa yang mempunyai kecerdasan interpersonal rendah. 2) Pada masing-masing kategori kecerdasan interpersonal siswa, bahwa antara siswa yang diberi model pembelajaran Jigsaw lebih baik prestasi belajarnya dibandingkan dengan siswa yang diberi model pembelajaran NHT maupun model pembelajaran langsung, dan siswa yang diberi model pembelajaran NHT menghasilkan prestasi belajar yang lebih baik daripada siswa yang diberi model pembelajaran langsung.

\section{SIMPULAN DAN SARAN}

Berdasarkan analisis data menggunakan analisis variansi dua jalan dengan sel tak sama, diperoleh kesimpulan bahwa: 1) siswa yang diberikan model pembelajaran Jigsaw menghasilkan prestasi belajar matematika lebih baik daripada siswa yang diberikan model pembelajaran NHT dan model pembelajaran langsung, dan siswa yang diberikan model pembelajaran NHT menghasilkan prestasi belajar matematika lebih baik daripada siswa yang diberikan model pembelajaran langsung pada pokok bahasan bangun ruang sisi datar, 2) siswa dengan kecerdasan interpersonal tinggi mempunyai prestasi belajar matematika yang sama baiknya dengan siswa yang mempunyai kecerdasan interpersonal sedang, siswa dengan kecerdasan interpersonal tinggi mempunyai prestasi belajar matematika yang lebih baik dibandingkan dengan siswa yang mempunyai kecerdasan interpersonal rendah, dan siswa dengan kecerdasan interpersonal sedang mempunyai prestasi belajar matematika yang sama baiknya dengan siswa yang mempunyai 
kecerdasan interpersonal rendah pada pokok bahasan bangun ruang sisi datar, 3) pada masing-masing model pembelajaran, siswa dengan kecerdasan interpersonal tinggi mempunyai prestasi belajar matematika yang sama baiknya dengan siswa yang mempunyai kecerdasan interpersonal sedang, siswa dengan kecerdasan interpersonal tinggi mempunyai prestasi belajar matematika yang lebih baik dibandingkan dengan siswa yang mempunyai kecerdasan interpersonal rendah, dan siswa dengan kecerdasan interpersonal sedang mempunyai prestasi belajar matematika yang sama baiknya dengan siswa yang mempunyai kecerdasan interpersonal rendah pada pokok bahasan bangun ruang sisi datar, serta 4) pada masing-masing kategori kecerdasan interpersonal siswa, siswa yang diberikan model pembelajaran Jigsaw menghasilkan prestasi belajar matematika lebih baik daripada siswa yang diberikan model pembelajaran NHT dan model pembelajaran langsung, dan siswa yang diberikan model pembelajaran NHT menghasilkan prestasi belajar matematika lebih baik daripada siswa yang diberikan model pembelajaran langsung pada pokok bahasan bangun ruang sisi datar.

Sesuai dengan simpulan dari penelitian ini, maka peneliti memberikan saran sebagai berikut. 1) Bagi guru, dalam menerapkan model pembelajaran kooperatif khususnya model pembelajaran Jigsaw, pembentukan kelompok belajar lebih memperhatikan heterogenitas siswa dalam suatu kelas, termasuk tingkatan kecerdasan interpersonal siswa. Hal ini dimaksudkan agar siswa dapat berdiskusi dan bekerjasama dengan baik dalam kelompok untuk tujuan bersama. Untuk kelas yang didominasi siswa dengan kecerdasan interpersonal tinggi, sedang maupun rendah, model pembelajaran Jigsaw dapat digunakan guru sebagai alternatif dalam proses pembelajaran. 2) Bagi peneliti lain, kesimpulan dari hasil penelitian ini dapat dikembangkan sebagai acuan atau salah satu referensi untuk penelitian yang relevan dan para peneliti dapat mengembangkan penelitian dengan mencoba membandingkan model pembelajaran Jigsaw dan NHT dengan model pembelajaran kooperatif lainnya, serta diharapkan dapat mengembangkan untuk variabel bebas yang lain, misalnya kecerdasan spasial, karena untuk dapat memahami konsep-konsep pada bangun ruang sisi datar diperlukan kecerdasan spasial yang memadai.

\section{DAFTAR PUSTAKA}

Ahmad dan Jazuli, A. 2009. Jigsaw Type of Cooperative Learning as a Means of Improving High School-Students' Mathematical Communication Ability. International Journal for Educational Studies. Vol. 1, No. 2, pp 207-218. 
Arianti Puspita Dewi. 2014. Eksperimentasi Model Numbered Heads Together dengan Make A Match (NHT MM) dan Numbered Heads Together dengan Bamboo Dancing (NHT BD) Ditinjau dari Kecerdasan Interpersonal. Jurnal Elektronik Pembelajaran Matematika. Vol. 2, No. 2, pp 193-201.

Baker, D. P. 2013. The Effects of Implementing The Cooperative Learning Structure, Numbered Heads Together, in Chemistry Classes at A Rural, Low Performing High School. Tesis: Louisiana State University.

Chan, D. W. 2005. Perceived Multiple Intelligences and Learning Preferences Among Chinese Gifted Students in Hong Kong. Journal for the Education of the Gifted. Vol. 29, No. 2, pp. 187-212.

Cheong, C. 2010. From Group-based Learning to Cooperative Learning: A Metacognitive Approach to Project-based Group Supervision. International Journal of an Emerging Transdiscipline. Vol. 13, pp 73-86.

Erlyn Yustantina. 2009. Model Pembelajaran Kooperatif Tipe Jigsaw dan Student Achievement Divisions (STAD) Ditinjau dari Kecerdasan Interpersonal Siswa. Tesis. Surakarta: Program Pascasarjana Universitas Sebelas Maret.

Ewing, B. 2011. Direct Instruction In Mathematics: Issues For Schools With High Indigenous Enrolments: A Literature Review. Australian Journal of Teacher Education. Vol. 36, No. 5, pp. 64-91.

Goos, M. 2004. Learning Mathematics in a Classroom Community of Inquiry. Journal of Research of Mathematics Education. Vol. 35, No. 4, pp 258- 291.

Katherine Her Pratiwi. 2013. Eksperimentasi Model Pembelajaran Kooperatif Tipe Jigsaw dan Numbered Heads Together (NHT) Ditinjau dari Kemandirian Belajar pada Prestasi Belajar Matematika Peserta Didik SMA Se-Kabupaten Magelang Tahun Pelajaran 2012/2013. Tesis. Surakarta: Program Pascasarjana Universitas Sebelas Maret.

Maheady, L., Michielle-Pendl, J., Harper, G., dan Mallette, B. 2006. The Effect of Numbered Head Together With and Without an Incentive Package on The Science Test Performance of a Diverse Group of Sixth Graders. Journal of Behavioral Education. Vol. 15, No. 1, pp 24-38.

Naomi, M. W. dan Githua, B. N. 2013. Effects of Jigsaw Cooperative Learning Strategy on Students' Achievement in Secondary School Mathematics in Laikipia East District, Kenya. Asian Journal of Management Sciences And Education. Vol. 2, No. 3, pp 177-188.

Paul Suparno. 2013. Teori Inteligensi Ganda dan Aplikasinya di Sekolah. Yogyakarta: Kanisius.

Senguil, S. dan Katranci, Y. 2012. Teaching the Subject, Sets' with the 'Dissociation and Re-Association' (Jigsaw). International Online Journal of Educational Sciences. Vol 4, No. 1, pp 1-18. 
Sulani. 2010. Eksperimentasi Model Pembelajaran Kooperatif Tipe Jigsaw Pada Materi Pokok Sistem Persamaan Linier Ditinjau dari Motivasi Belajar Siswa Kelas X SMA Negeri Se-Kabupaten Tulungagung Tahun Ajaran 2009/2010. Tesis. Surakarta: Program Pascasarjana Universitas Sebelas Maret.

Sulistyana. 2013. Eksperimentasi Pembelajaran 'Think-Pair-Share' dengan Pendekatan Matematika Realistik dan 'Numbered Heads Together' dengan Pendekatan Matematika Realistik Terhadap Prestasi Belajar Matematika Ditinjau Dari Kecerdasan Interpersonal Siswa di Kabupaten Gunungkidul. Tesis. Surakarta: Program Pascasarjana Universitas Sebelas Maret.

Tran, V. D. dan Lewis, R. 2012. The Effects of Jigsaw Learning on Students' Attitudes in a Vietnamese Higher Education Classroom. International Journal of Higher Education. Vol. 1, No. 2, pp 9-20.

Xie, J. C. dan Lin, R. L. 2009. Research on Multiple Intelligences Teaching and Assessment. Asian Journal of Management and Humanity Sciences. Vol. 4, No. 2-3, pp. 106-124.

Zakaria, E. dan Iksan, Z. 2007. Promoting Cooperative Learning in Science and Mathematics Education: A Malaysian Perspective. Eurasia Journal of Mathematics, Science and Technology Education. Vol. 3, No. 1, pp 35-39.

Zarei, A. A. dan Mohseni, F. 2012. On the Relationship Between Multiple Intelligences and Grammatical and Writing Accuracy of Iranian Learners of English. Journal of New World Sciences Academy. Vol. 10, No. 7, pp 1306-1317. 